\title{
Influence of Bolus Volume on Hyoid Movements in Normal Individuals and Patients with Parkinson's Disease
}

\author{
Axel R. Wintzen, Umesh A. Badrising, Raymund A.C. Roos, Jan Vielvoye \\ and Lishya Liauw
}

\begin{abstract}
The swallowing movements of 22 ambulant patients with Parkinson's disease were examined by videofluoroscopy, 15 spouses serving as controls. The relation between bolus volume and movement of the hyoid bone was studied in the lateral view to assess the adaptation of the pharynx musculature. Although movement characteristics of the hyoid varied considerably both intra- and interindividually, mean values followed typical patterns. In controls, the position of the hyoid before the start of the swallow tended to be lower as the bolus volume increased, apparently to create space in the oral cavity by lowering the floor of the mouth. This trend was not seen in the group of Parkinson patients. We suppose that this specific lack of adaptation represents hypokinesia. The amplitude of the hyoid movement did not change with increasing bolus volumes, either in patients or in controls. Moreover, Parkinson patients had many more aborted swallowing movements ("hesitations") than controls, probably representing defective switching from the voluntary phase of swallowing to the involuntary, automatic phase.
\end{abstract}

\begin{abstract}
Résumé: Influence du volume du bolus sur les mouvements hyoïdiens chez des individus normaux et chez de patients atteints de la maladie de Parkinson. Nous avons examiné par vidéofluoroscopie les mouvements de déglutition chez 22 patients ambulants atteints de la maladie de Parkinson et chez 15 conjoints(es) servant de contôles. Nous avons étudié la relation entre le volume du bolus et les mouvements de l'os hyoïde en vue latérale pour évaluer l'adaptation de la musculature pharyngée. Bien que les caractéristiques du mouvement de l'os hyoïde variaient considérablement chez un même individu et entre les individus, les valeurs moyennes avaient des profils typiques. Chez les contrôles, la position de l'os hyoïde avant le début de la déglutition avait tendance à être plus basse quand le volume du bolus augmentait, pour créer, semble-t-il, de l'espace dans la cavité buccale en abaissant le plancher de la bouche. Cette tendance n'était pas observée dans le groupe de patients. Nous supposons que ce manque d'adaptation spécifique représente de l'hypokinésie. L'amplitude du mouvement hyö̈dien ne changeait pas avec l'augmentation du volume du bolus chez les patients ou chez les contrôles. De plus, les patients avaient beaucoup plus de mouvements de déglutition avortés ("hésitations") que les contrôles, ces mouvements étant probablement une transition défectueuse de la phase volontaire à la phase automatique involontaire de la déglutition.
\end{abstract}

Can. J. Neurol. Sci. 1994; 21: 57-59

The swallowing movement is adjusted to varying demands of different bolus characteristics such as consistency, viscosity, elasticity, volume, and to different head and neck postures. ${ }^{1}$

Several abnormal swallowing patterns have been observed in patients with Parkinson's disease (PD); they comprise changes such as abnormal bolus formation, abnormal tongue movements, delayed swallowing reflex, piece-meal deglutition, decreased pharyngeal peristalsis, vallecular and piriform sinus residue, and aspiration. ${ }^{2-5}$

During the swallowing movement, aspiration is prevented both by ventro-cranial movement of the larynx and by its closure by means of the backfolding epiglottis. In the very complex movement required, the hyoid bone takes a central role. Its movements can be easily measured in the lateral fluoroscopic view.
The aims of the present study were to quantify the hyoid movement characteristics of swallowing in PD and to investigate the influence of bolus volumes on these characteristics in PD and in controls.

\section{SUBJECTS AND METHODS}

\section{Subjects}

Twenty-two out-patients with idiopathic Parkinson's disease, 17 men and 5 women (mean [SD] age, 62.7 [9.9] years) were

From the Department of Neurology (A.R.W., U.A.B., R.A.C.R.), and the Department of Neuroradiology (G.J.V., L.L.). University of Leiden. The Netherlands.

RECEIVED APRIL 19, 1993. ACCEPTED JUL.Y 26. 1993. 1993.

Reprim requests to: A.R. Wintzen, gebouw 20 AZI, Postbus 9600. 2300 RC Leiden. The Netherlands. 
recruited. They were in modified Hoehn and $\mathrm{Yahr}^{6}$ stage 1.5 $(n=4), 2(n=7), 2.5(n=5), 3(n=3)$ or $4(n=3)$; their mean (range) UPDRS ${ }^{6}$ rating was 31 (14-86), whereas their mean duration of illness was $6.7(3.7,3-18)$ years. Patients with dementia (Mini-Mental State $<24$ ), ${ }^{7}$ apparent depression, Stage 5 of Hoehn and Yahr, other neurological or internal disorders interfering with swallowing or pulmonary function were excluded.

Spouses of the patients were asked to serve as controls. They completed a small questionnaire about their general health. This group comprised 4 men and 11 women with a mean age of 63.0 $(9.7)$ years.

\section{MeThods}

Ten patients had discontinued their anti-Parkinson medication on our request, from midnight until examination at about 11 a.m. whereas the remaining 12 preferred to continue. All subjects were studied under standard conditions. They were seated upright with their heads in neutral position. To minimize associated movements of the head and cervical spine, subjects were asked to stabilise their heads against an occipital support device. They were also asked to keep their teeth closed during swallowing, as previously performed tests and literature ${ }^{8}$ had made clear that some subjects have the tendency to drop the mandible during the swallowing movement to provide extra space for larger bolus volumina.

Each subject successively swallowed 5 different volumes of barium-opaque fluid, 3, 6, 9, and $12 \mathrm{ml}$ successively, followed by a "dry swallow" $(0 \mathrm{ml})$. Videofluoroscopy and a 48 images/second videocountertimer were used to record the movements of pharynx and cervical oesophagus in the lateral projection. Movements of the hyoid bone were analyzed frame by frame. A transparent sheet was fixed upon the monitor screen, to follow the position of the hyoid during the swallowing movement, providing a time-place diagram. The direction of the axis parallel to the cervical spine was chosen as the Y-axis of the hyoid movement. The height of C3 was taken as a measure of length. The features studied comprised the vertical distance between the starting and the final (= "resting") hyoid position, referred to as "displacement", the maximum vertical hyoid movement (= "amplitude") during "complete" swallowing and its amplitude during "hesitations", i.e., aborted swallowing movements. For detailed description and definitions, see Figures $\mathrm{IA}$ and $\mathrm{IB}$.

In case of multiple swallows for one bolus, the resting position after the last swallow was used.

The study was approved by the Medical Ethical Committee of the Leiden Academic Hospital. Informed consent was given by patients and spouses.

\section{Results}

During the movement in superior direction, the hyoid bone occasionally moved behind the mandible in 5 subjects. Of these, the bone could be detected through the mandibular shadow in 2 cases, but was lost in 3 persons. In the latter, the mandibular edge was substituted for the most cranial position. The resulting error was neglected. One patient was excluded because the hyoid shadow was so faint that it was repeatedly lost. Patients who had discontinued their medication showed similar mean values for all measured variables as the patients who had not. Mean values did not differ between sexes. Accordingly, all patients were analyzed as one single group.
Table 1. Displacement and amplitude of the hyoid movement in patients and controls related to bolus volume.

\begin{tabular}{lcccc}
\hline & $\begin{array}{c}\text { Volume } \\
(\mathbf{m l})\end{array}$ & $\begin{array}{c}\text { Patients } \\
(\mathbf{n}=\mathbf{2 1})\end{array}$ & $\begin{array}{c}\text { Controls } \\
(\mathbf{n}=\mathbf{1 5})\end{array}$ & P-value $^{1}$ \\
\hline Mean displacement (SD) & 0 & $-3.3(16)$ & $-1.7(21)$ & 0.810 \\
(\% vertebral height C3) & 3 & $-3.1(25)$ & $-25.7(28)$ & 0.018 \\
& 6 & $-2.4(27)$ & $-22.3(28)$ & 0.040 \\
& 9 & $-3.6(26)$ & $-38.2(26)$ & 0.001 \\
& 12 & $-6.7(29)$ & $-32.1(27)$ & 0.012 \\
\hline Mean amplitude (SD) & 0 & $1.3(0.4)$ & $1.2(0.3)$ & \\
(* vertebral height C3) & 3 & $1.2(0.4)$ & $1.0(0.3)$ & \\
& 6 & $1.1(0.4)$ & $1.0(0.3)$ & \\
& 9 & $1.2(0.4)$ & $1.0(0.3)$ & \\
& 12 & $1.2(0.5)$ & $1.1(0.3)$ & \\
\hline
\end{tabular}

'For the difference between patients and controls, Student t-test for two groups, one-tailed. P-values for differences in amplitude are $>0.05$.

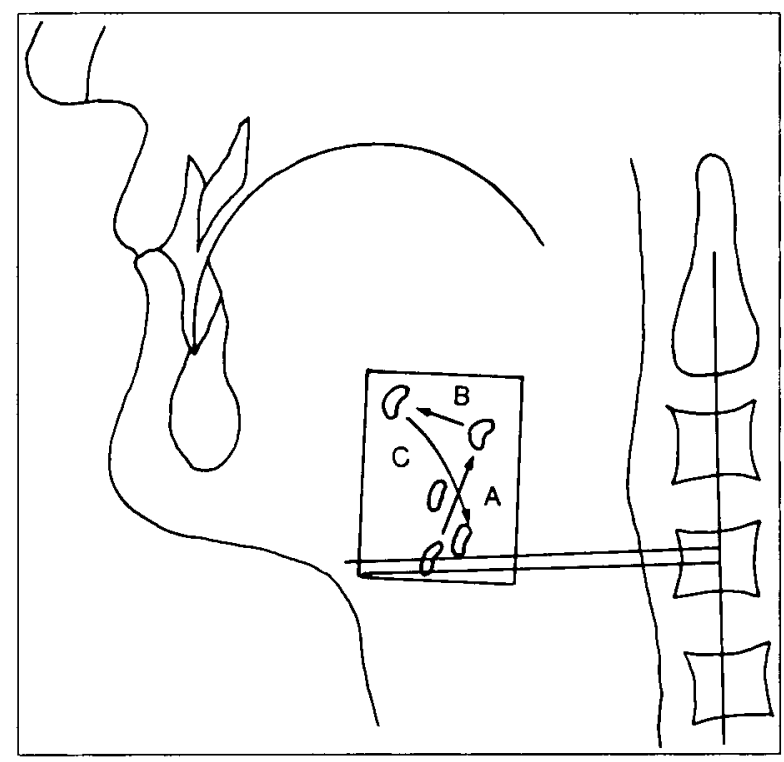

Figure 1A: Graph show's the normal movement of the hyoid during swallowing in lateral projection. A: hyoid moves craniodorsally. $B$ : hyoid moves cranioventrally. C: hyoid moves dorsocaudally.

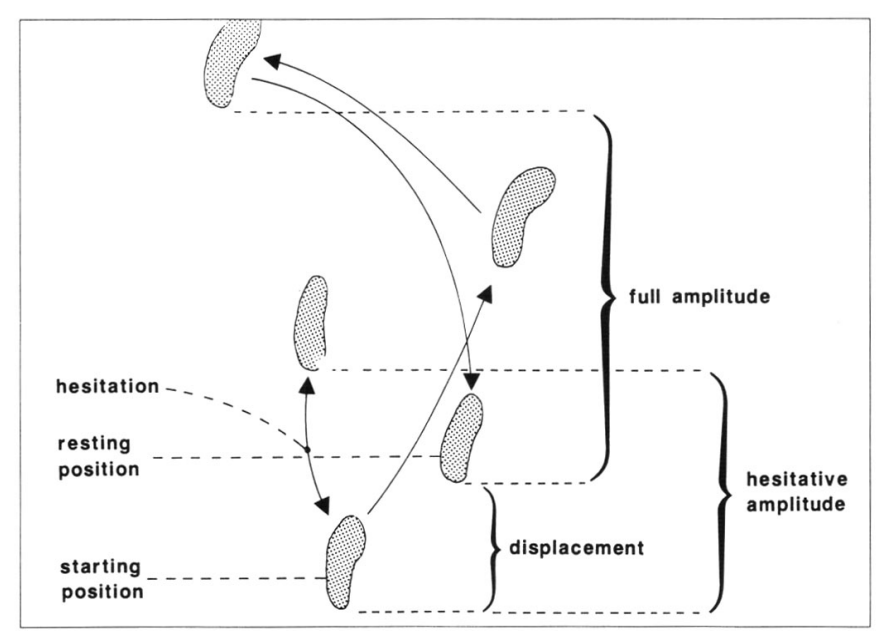

Figure 1B: Definitions of movement characteristics of the hyoid bone in lateral view. 


\section{Vertical Hyoid Displacement in Relation to the Bolus Volume (Table 1)}

With a dry swallow the starting position of the hyoid was approximately equal to that at the end of the swallowing movement (resting position) in both patients and controls. With volumes larger than $0 \mathrm{ml}$ the starting position of the hyoid bone of controls consistently tended to be lower than the resting position. By contrast, the starting position of the hyoid bone of patients did not change with increasing bolus volumes. It should be noted that variations of displacement were considerable. A regular pattern emerged, however, after calculation of mean values.

\section{Vertical Amplitude of the Hyoid Movement in Relation to the Bolus Volume (Table 1)}

Swallows with increasing bolus volumes showed no evident variation in amplitude, neither in patients nor in controls. The average amplitude for patients and controls at all volumes was similar.

\section{Amplitude of Hesitations in Relation to the Amplitude of Complete Swallowing Movements}

We counted a total number of 57 hesitations of the hyoid in patients vs. 11 in controls.

The magnitude of the amplitudes of complete swallowing movements was significantly correlated with the magnitude of amplitudes of hesitations ( $n=68, r=0.67, p<0.01$ ). The average amplitude of a hesitation was about half the magnitude of the superior excursion of the hyoid (mean [SD], 50.6\% [14.3]).

\section{Discussion}

In "dry" swallows, the hyoid returned to its starting point, underlining the cyclic nature of this movement. In controls, the starting point was lowered proportionally to the bolus volume. We assume that this displacement represents one of the adaptive mechanisms to create space in the oral cavity, being the result of lowering the floor of the mouth. This bolus volume-related displacement has been observed by others, ${ }^{8.9}$ although it was interpreted in a somewhat different way. Surprisingly, this adaptive descent of the hyoid was not seen in the group of Parkinson patients. This lack of adaptation to larger boluses was interpreted as a form of hypokinesia. This leaves us with the question how Parkinson patients enlarge their oral cavity to accommodate larger volumes. Alternative ways are lowering of the mandible and filling the cheek-pouches. The first possibility was excluded by asking the subjects to close their teeth. The second possibility, filling the cheek-pouches, is suspected in some subjects, but has not been investigated systematically.

Another finding was the normal amplitude of the hyoid movement in Parkinson patients. Thus, hypokinesia does not seem to be expressed in this aspect of movement.

A third observation was the increased frequency of hesitations in Parkinson patients. The amplitude of these abortive movements was similar to that of controls: about $50 \%$ of the "completed" movements. An increased proportion of hesitations has been described as an age-related phenomenon. ${ }^{10}$ This cannot be the explanation in our patients, as the controls had a similar agedistribution. Therefore, we suppose that the high rate of hesitations in PD reflects the increased difficulty in switching from the voluntary initiation of the swallow to the automatic continuation, resembling the well known problem of switching to the automatism of walking in PD.

\section{REFERENCES}

1. Buchholz DW, Bosma JF, Donner MW. Adaptation, compensation, and decompensation of the pharyngeal swallow. Gastrointest Radiol 1985; 10: 235-239.

2. Stroudley J, Walsh M. Radiological assessment of dysphagia in Parkinson's disease. Br J Radiol 1991; 64: 890-893.

3. Bushmann M, Dobmeyer SM, Leeker L, Perlmutter JS. Swallowing abnormalities and their response to treatment in Parkinson's disease. Neurology 1989; 39: 1309-1314.

4. Robbins JA, Logemann JA, Kirshner HS. Swallowing and speech production in Parkinson's disease. Ann Neurol 1986; 19: 283287.

5. Lieberman AN, Horowitz L, Redmond $P$, et al. Dysphagia in Parkinson's disease. Am J Gastroenterol 1980; 74: 157-160.

6. Fahn S, Elton RL, members of the UPDRS Development Committee. Unified Parkinson's disease rating scale. In: Fahn S, Marsden CD, Calne DB, Goldstein M, eds. Recent Developments in Parkinson's Disease, Vol. 2. Florham Park, NJ: MacMillan Healthcare Information, 1987: 153-163.

7. Folstein MF, Folstein SE, McHugh PR. Mini-Mental State: a prac tical method for grading the cognitive state of patients for the clinician. J Psychiatr Res 1975; 12: 189-198.

8. Dodds WJ, Man KM, Cook IJ, et al. Influence of bolus volume on swallow-induced hyoid movement in normal subjects. Am J Radiol 1988; 150: 1307-1309.

9. Dantas RO, Kern MK, Massey BT, et al. Effect of swallowed bolus variables on oral and pharyngeal phases of swallowing. Am J Physiol 1990; 258: G675-G681.

10. Sonies BC, Parent LJ, Morrish K, Baum BJ. Durational aspects of the oral-pharyngeal phase of swallow in normal adults. Dysphagia 1988; 3: 1-10. 